\title{
Attichy - L'Avenue
}

Sylvie Alexandre, Denis Maréchal et Farid Simon

URL : http://journals.openedition.org/adlfi/4562

ISSN : 2114-0502

Éditeur

Ministère de la culture

Référence électronique

Sylvie Alexandre, Denis Maréchal et Farid Simon, «Attichy - L'Avenue », ADLFI. Archéologie de la France - Informations [En ligne], Picardie, mis en ligne le 01 mars 2006, consulté le 19 avril 2019. URL : http:// journals.openedition.org/adlfi/4562

Ce document a été généré automatiquement le 19 avril 2019

(c) Ministère de la Culture et de la Communication, CNRS 


\title{
Attichy - L'Avenue
}

\author{
Sylvie Alexandre, Denis Maréchal et Farid Simon
}

Identifiant de l'opération archéologique : 9019

Date de l'opération : 2006 (MH)

1 La fouille, dans cette future carrière, fait suite aux résultats du diagnostic mené sous la direction de M. Friboulet (Inrap) en 2005. La parcelle se situe dans la vallée de l'Aisne, sur sa rive droite. Le cours d'eau coule à $625 \mathrm{~m}$ au sud du gisement. Le site est placé sur la première terrasse de la rivière. Un paléochenal se développe à moins de $100 \mathrm{~m}$ du bord du décapage. Il suffit de retirer $0,30 \mathrm{~m}$ à $0,50 \mathrm{~m}$ d'épaisseur de terre végétale pour percevoir l'encaissant sableux ou plus rarement des nappes de gravier fin. Le décapage a porté sur une surface de $2600 \mathrm{~m}^{2}$ et quatre-vingt-treize structures distinctes sont apparues, majoritairement antiques. Cette implantation qui se développe, probablement pour l'essentiel, hors emprise (à l'ouest), comporte des clôtures avec des trous de poteau, des fossés, des fosses, des fosses d'extraction et une vaste mare. Cette dernière, de forme irrégulière, mesure entre $25 \mathrm{~m}$ et $30 \mathrm{~m}$ de diamètre et sa profondeur atteint au maximum $0,65 \mathrm{~m}$, mais le plus souvent $0,50 \mathrm{~m}$. Elle se situe dans la partie basse du site, soit juste sous la rupture de pente observée sur le décapage. Elle tire, sans doute, partie d'une dépression naturelle. Testée par des tranchées, la mare a été curée à plus de $75 \%$. Les stratigraphies montrent une dynamique de remplissage complexe qui permet d'estimer quatre états au minimum (autour de $400 \mathrm{~m}^{2}$ ou $500 \mathrm{~m}^{2}$ pour chaque phase?). Les fossés servent dans la zone basse à drainer le terrain, alors que plus haut, ils définissent des espaces qui s'imbriquent. Une entrée large de 2,15 $\mathrm{m}$ a été observée dans l'un de ces derniers. Ils mesurent entre $0,50 \mathrm{~m}$ et $1,10 \mathrm{~m}$ de large pour une profondeur comprise entre $0,05 \mathrm{~m}$ et $0,32 \mathrm{~m}$, ce qui témoigne de la forte érosion. À ces délimitations il faut donc adjoindre trois clôtures. La plus petite est perçue sur un peu plus de $7 \mathrm{~m}$, tandis que les autres se développent sur $23 \mathrm{~m}$ à $32 \mathrm{~m}$ de long. Les poteaux sont distants régulièrement de $0,30 \mathrm{~m}$ à $0,50 \mathrm{~m}$, mais des écarts plus importants sont fréquents (ouverture ?; effacés par l'érosion?). Orientées globalement dans le sens de la pente, ces 
barrières sont recoupées par les fossés et s'interrompent au niveau de la mare ou quelques mètres avant. Un décalage d'orientation existe (de $15^{\circ}$ ) et les morphologies diffèrent aussi, donc rien n'accrédite leur synchronie. Quelques fosses ont également été identifiées. Certaines sont atypiques. La plus longue (6,80 m x 3,05 $\mathrm{m}$ x 0,25 m), dont les angles sont arrondis, pourrait correspondre à un vide sanitaire. Deux autres, qui dessinent des quadrilatères $(2,50 \mathrm{~m} \times 2,30 \mathrm{~m} \times 0,45 \mathrm{~m}$ et $1,75 \mathrm{~m} \times 1,7 \mathrm{~m} \times 0,42 \mathrm{~m})$ aux bords verticaux, pourraient correspondre à des celliers. Il faut noter que l'un des deux contenait plus de $70 \mathrm{~kg}$ de céramique, outre de nombreux fragments de meules en poudding et que ce matériel a subi l'action de la chaleur. Plusieurs éléments en bronze évoquent aussi des pièces d'harnachement. Enfin, une autre catégorie de fosses est représentée par de petites carrières. De formes variées, mais irrégulières, leurs fonds sont peu profonds ( $0,20 \mathrm{~m}$ maximum) et presque plats. Plusieurs sont partiellement oblitérées par la mare principale. Elles peuvent être liées à l'extraction de sable ? La chronologie du site couvre depuis la période précoce jusqu'au milieu du $\mathrm{III}^{\mathrm{e}} \mathrm{s}$. Il est délicat d'interpréter cette portion d'établissement, fortement arasée et qui se développe hors emprise. Un important hiatus chronologique existe ensuite, puisqu'il faut attendre la période moderne pour observer d'autres structures. Celles-ci se présentent sous la forme de deux rangées de fosses quadrangulaires, distantes de $5 \mathrm{~m}$. Elles sont longues en moyenne de $3 \mathrm{~m}$ pour une largeur de $1,80 \mathrm{~m}$. Le profil dessine un pallier à $0,20 \mathrm{~m}$, alors que le fond plat est entre $0,30 \mathrm{~m}$ et $0,45 \mathrm{~m}$. Elles sont quasiment vides de tout mobilier et les comblements, uniques, sont similaires. Il pourrait s'agir des fosses de plantations des arbres qui bordaient un chemin du XVIII $^{e}$ s. et dont le départ se trouvait au niveau du château d'Attichy.

2 MARÉCHAL Denis (Inrap), ALEXANDRE Sylvie (Inrap), SIMON Farid (Inrap)

INDEX

Index chronologique : Empire romain, Temps Modernes

operation Fouille avant travaux (MH)

Thèmes : acquisition de ressource naturelle

Index géographique : Picardie, Oise, Attichy

\section{AUTEURS}

SYLVIE ALEXANDRE

INRAP

DENIS MARÉCHAL

INRAP 
FARID SIMON

INRAP 